\title{
Desafios de adequação à questão ambiental em frigoríficos na cidade de São Luís, Maranhão: diagnóstico de situação
}

\author{
Challenges of adapting to environmental issue in cold storages in the city of \\ São Luís, Maranhão: situation diagnosis
}

\author{
Janayna Jordânia Nunes dos Santos ${ }^{1}$, Isabela Christie dos Santos Sousa ${ }^{1}$, Danilo Cutrim Bezerra', \\ Viviane Correia da Silva Coimbra ${ }^{2}$, Nancyleni Pinto Chaves ${ }^{1 *}$
}

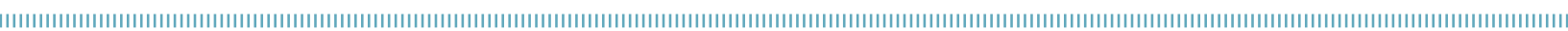

RESUMO: O presente trabalho foi realizado com o objetivo de elaborar um diagnóstico dos desafios de adequação à questão ambiental em frigoríficos na cidade de São Luís, Maranhão. Para a realização deste estudo foram efetuadas entrevistas e coletas de amostras de efluente líquido em três frigoríficos que abatem bovinos, no período de setembro a dezembro de 2012. Foram analisadas também as ações empreendidas e a postura da empresa com relação às questóes ambientais. Os impactos ambientais do abate de bovinos na cidade de São Luís, Maranhão, envolve uma série de questôes, com destaque para o armazenamento e transporte incorreto dos resíduos sólidos, alta dependência de água, emissão de efluentes em desconformidade com a legislaçáo vigente e liberação de odor fétido. A partir das entrevistas foi possível constatar que as principais limitaçóes das empresas para a sustentabilidade ambiental são a não valorização do meio ambiente e a ausência de uma liderança para defesa e difusão dessa questáo. Dessa forma, conclui-se que os frigoríficos na cidade de São Luís, Maranhão, não estáo preocupados em manter seu processo produtivo sem causar danos ao meio ambiente.

PALAVRAS-CHAVE: resíduos; efluentes; abate de bovinos; sustentabilidade ambiental.

\begin{abstract}
The present study was performed in order to make a diagnosis of the challenges of adapting to environmental issue in cold storages in São Luís, Maranhão, Brazil. For this study, interviews were conducted and samples of liquid effluent were collected from three cold storages that slaughter cattle in the period from September to December 2012. We also evaluate the actions undertaken and the company's position regarding environmental issues. The environmental impacts of cattle slaughter in São Luís, Maranhão, involve a number of issues, especially the incorrect storage and transportation of solid waste, high dependence on water, wastewater emissions in disagreement with the current legislation and the release of aversive odors. From the interviews, it was possible to notice that the main limitations of the company for its environmental sustainability are not to value the environment and the lack of a leadership to defense and disseminate this matter. Thus, we conclude that the cold storages in São Luís, Maranhão, are not concerned with keeping their production process without harming the environment.
\end{abstract}

KEYWORDS: wastes; effluents; cattle slaughter; environmental sustainability.

\footnotetext{
'Curso de Zootecnia; Departamento de Zootecnia; Universidade Estadual do Maranhão (UEMA) - São Luís (MA), Brasil.

${ }^{2}$ Agência Estadual de Defesa Agropecuária do Maranhão (AGED-MA) - São Luís (MA), Brasil.

*Autor correspondente: nancylenichaves@hotmail.com

Recebido em: 15/01/2013. Aceito em: 25/09/2014.
} 


\section{INTRODUÇÃO}

O Brasil, atualmente, possui o maior rebanho comercial de bovinos do mundo, ocupa a segunda posição entre os países produtores e assumiu a liderança mundial na quantidade de carne exportada. A pecuária de corte é uma das explorações agropecuárias mais significativas, tanto na geração de receitas internas como na pauta de exportação, e ainda incorpora tecnologias que aumentam a produtividade. $\mathrm{O}$ rebanho comercial brasileiro possui cerca de 204,7 milhóes de cabeças (IBGE, 2011). O país tem a segunda maior produção mundial com cerca de 9,77 milhóes de toneladas em equivalente carcaça (ABIEC, 2011). O que comprova o potencial brasileiro como fabricante de produtos como couro e carne bovina (Araújo et al., 2007).

Atualmente, o Maranhão apresenta o segundo maior contingente de bovinos da região Nordeste, com 6.885.265 animais (IBGE, 2011). E o cenário maranhense vem apresentando mudanças significativas, pois a especializaçáo da produção tem alterado o perfil da pecuária bovina de corte local, passando de atividade de cria e recria para uma pecuária de cria, recria, engorda, abate e processamento no próprio estado, na qual a adoção de novas tecnologias é fundamental para a competitividade do setor. O Maranháo, com a atual classificação de livre de febre aftosa com vacinação, caracteriza-se como um estado de grande potencial pecuário, não somente para criação de rebanhos bovinos, mas também para a industrialização de seus produtos (processamento de carnes e derivados, couro, leite, etc.).

O segmento industrial da cadeia produtiva de carne bovina compreende dois setores distintos, o produtivo e o de abate. As empresas que normalmente atuam no abate de animais são os abatedouros e os frigoríficos com processamento e industrialização de carnes (Morales, 2006). O abate de bovinos, assim como de outras espécies animais, é realizado para a obtenção de carne e de seus derivados destinados ao consumo humano (Pacheco; Yamanaka, 2008).

A indústria de abate e processamento de carnes participa de forma relevante na atividade econômica brasileira, no tocante ao volume de produção e exportaçôes e à capacidade de geração de empregos (cerca de 500 mil empregos diretos) (SARDA et al., 2009). Entretanto, a consequência do surgimento de um número crescente de abatedouros e frigoríficos é o aumento da quantidade e complexidade dos resíduos gerados e lançados no ambiente por esses estabelecimentos (NiETO, 2000).

Do abate de bovinos resultam grandes quantidades de resíduos líquidos, semissólidos e sólidos, como couros, sangue, ossos, gorduras, aparas de carne, vísceras, animais ou suas partes condenadas pela inspeção sanitária, entre outros, que são poluentes e, por isso, necessitam de uma adequada separação e tratamento, antes de serem lançados no meio ambiente (FERnANDEs, 2004).
Os resíduos de abatedouros e frigoríficos são preocupantes por possuírem altos valores de demanda bioquímica de oxigênio (DBO) oscilando de 800 a 32.000 mg/L (Braile, 1993). Devido à constituição dos sólidos, com presença de gorduras e proteínas, apesar de ambas serem biodegradáveis, são dotadas de alta putrescibilidade, com início de decomposição em poucas horas, liberando odor fétido, o que torna extremamente desagradável a atmosfera na circunvizinha de tais estabelecimentos (Prata, 1999; Pacheco, 2006).

Associado a isso, em frigoríficos o alto consumo de água acarreta grandes volumes de efluentes, considerando que 80 a 95\% da água consumida são descarregadas como efluente líquido. Esses efluentes caracterizam-se principalmente por: alta carga orgânica, devido à presença de sangue, gordura, esterco, conteúdo estomacal não digerido e conteúdo intestinal; flutuaçôes de potencial hidrogeniônico $(\mathrm{pH})$ em função do uso de agentes de limpeza ácidos e básicos; altos conteúdos de nitrogênio, fósforo e sal e flutuaçóes de temperatura — uso de água quente e fria (Pacheco; Yamanaka, 2008).

Indiscutivelmente, o efluente de frigoríficos é responsável por uma imagem negativa do público em relação a esses estabelecimentos e as autoridades sanitárias veem nele o grande poluidor dos mananciais das águas de abastecimento (Morales, 2006; Silva, 2011).

Em inúmeros frigoríficos não estão disponíveis sistemas adequados de disposição dos resíduos gerados, desencadeando sérios problemas ecológicos e episódios com graves consequências para a saúde pública (NiETo, 2000). Diferente de outras indústrias em que a certificação ambiental pela norma ISO 14000 (ABNT, 2004) é comum, apresentando um número considerável de empresas certificadas, para o setor de processamento de carne a quantidade é incipiente (FERnANDes, 2004).

$\mathrm{O}$ ciclo produtivo da sociedade capitalista extrai do meio ambiente os insumos necessários para a produção de alimentos e bens de consumo, entretanto, o processo produtivo retorna resíduos e emite poluentes em grandes quantidades, acarretando poluição e esgotamento dos recursos naturais. A finitude dos recursos naturais e os impactos negativos dos resíduos das indústrias, apontados por SEvero et al. (2006), resultaram em um processo de desenvolvimento econômico sem preocupação com a natureza e com a qualidade de vida.

As empresas procuram resultados financeiros, ampliaçáo de fatias de mercado, sobrevivência e manutenção de sua competitividade. A globalização da economia e o acirramento da competição mundial elevam a escala de produção, com a consequente busca da redução dos custos. Entretanto, Ribeiro (2006) afirmou que o processo de incorporação da sustentabilidade empresarial é, em grande parte, influenciado e estimulado pelas pressóes da sociedade civil ou por perdas associadas às questóes econômicas. $\mathrm{O}$ grande desafio que surge é provar que os investimentos nessa área são sinônimos de empreendimentos mais produtivos, que adaptam a força de trabalho, 
catalisam o aumento da oferta de energias renováveis, utilizam tecnologias limpas e trazem retornos financeiros.

Diante da problemática relacionada aos estabelecimentos de abate, do nítido crescimento dessa atividade e da sua importância econômica, social e ambiental associados ao pioneirismo deste trabalho na cidade de São Luís, Maranhão, é que se realizou esta pesquisa com o objetivo de elaborar um diagnóstico dos desafios de adequação à questão ambiental em frigoríficos na cidade de São Luís, Maranhão.

\section{MATERIAL E MÉTODOS}

\section{Local do estudo}

O presente estudo possui um desenho descritivo com uma abordagem quantitativa e qualitativa. $\mathrm{O}$ universo da pesquisa foi composto por três frigoríficos sob Serviço de Inspeção Municipal localizados no distrito industrial da cidade de São Luís, Maranhão.

Os três estabelecimentos são responsáveis conjuntamente pelo abate de aproximadamente 10.400 animais/mês oriundos de todo o estado do Maranháo e de outros estados, como Pará. O abastecimento de feiras, mercados e supermercados é realizado em $90 \%$ por esses estabelecimentos, sendo uma importante atividade econômica para a cidade de São Luís, Maranhão.

\section{Coleta de dados}

A coleta de dados foi realizada no período de setembro a dezembro de 2012, com a aplicação de questionários compostos por perguntas abertas, aplicados intencionalmente a três funcionários (supervisor da área de manutenção, técnico da estação de tratamento de efluentes e responsável técnico pelo frigorífico), mediante a assinatura do Termo de Conhecimento Livre e Esclarecido. A escolha desses funcionários justifica-se pelo fato de atuarem e conhecerem o processo produtivo da empresa.

As variáveis da pesquisa que orientaram a elaboração do questionário e a avaliação dos riscos ambientais do abate de bovino foram os seguintes:

1. Resíduos sólidos: cabeças, pés, vísceras e carcaças condenadas, ossos, peles, gorduras, borra do flotador e resíduos dos currais oriundos da lavagem;

2. Resíduos líquidos: sangue, água oriunda da higienização da planta frigorífica e água oriunda da toalete das carcaças e vísceras;

3. Destinos dos resíduos: locais de armazenamento até o momento de seu processamento;

4. Quantidades de resíduos sólidos e líquidos provenientes do processo de abate de bovinos;
5. Legislação: instrumento que regula a prevenção, o controle e a responsabilização dos agentes poluentes.

\section{Coleta de efluente líquido}

Em cada frigorífico foram coletadas duas amostras de efluente líquido da estação de tratamento (lagoa facultativa), em triplicata, com intervalo bimestral entre as coletas, no período de setembro a dezembro de 2012, pela manhá. No momento das coletas foram aferidas as temperaturas da água e do ar, e avaliadas a presença de sólidos suspensos e a vazáo máxima.

A metodologia de coleta seguiu as normas estabelecidas pela Associação Brasileira de Normas Técnicas (ABNT, 1988). As análises físico-químicas foram realizadas no Laboratório de Solos da Universidade Estadual do Maranhão (UEMA) e no Laboratório de Patologia Clínica LTDA, laboratório particular da cidade de São Luís, Maranhão.

As análises foram procedidas de acordo com as técnicas recomendadas pelo Standard Methods for the Examination of Water and Wastewater da America Water Works Association (ApHA, 1995), e foram avaliados os seguintes parâmetros: $\mathrm{pH}$, $\mathrm{DBO}$, demanda química de oxigênio (DQO), fosfato, óleos e graxas, sólidos suspensos, sólidos totais, sólidos dissolvidos, sólidos sedimentáveis, sulfito, nitrito e nitrato. Os resultados foram interpretados com base na Resolução no 430, de 13 de maio de 2011, do Conselho Nacional do Meio Ambiente (CONAMA) (Brasil, 2011).

\section{Georreferenciamento dos dados}

Para o georreferenciamento dos dados foi utilizado aparelho GPS5 modelo Garmin ${ }^{\circledR}$ para tomada de coordenadas geográficas dos frigoríficos e da fábrica de subprodutos. Dessa forma, cada endereço foi localizado em um ponto no espaço. Para a confecção do mapa temático foi utilizado o programa GPS TrackMaker $^{\circledR}$ v. 13,0 .

\section{Análise estatística}

Para verificar se existiam diferenças significativas ao nível de 5\% entre os frigoríficos estudados em relação à produção de resíduos sólidos e líquidos foram realizadas a análise de variância (ANOVA) seguida do teste de Tukey e a análise de correlação utilizando o software STATISTICA 5.1 (STATSOFt, Inc, 1998) segundo os critérios propostos por ARANGO (2001).

\section{RESULTADOS E DISCUSSÃO}

Da análise dos questionários aplicados aos funcionários dos frigoríficos encarregados dos destinos finais dos dejetos do abate de bovinos foram identificados os seguintes tipos de resíduos com 
fins comerciais: unhas, cabeças, restos de ossos e peles, restos de carcaças e vísceras condenadas, gorduras e esterco. Os tipos sem fins comerciais identificados foram sangue e efluente líquido. Dessa forma, os resíduos gerados no processo de abate de bovinos na cidade de São Luís, Maranhão, geralmente são aqueles que possuem pouca ou nenhuma finalidade industrial.

A Tabela 1 apresenta os tipos de resíduos sólidos derivados do abate de bovinos nos frigoríficos estudados, bem como a sua quantidade média mensal gerada.

Em relação à avaliação estatística fundamentada na análise de variância (ANOVA) seguida do teste de Tukey, verificaram-se que náo existiam diferenças significativas $(p>0,05)$ entre os frigoríficos quanto à produçáo de resíduos sólidos. Apesar da diferença no número de animais abatidos entre as empresas (frigorífico A: 100 animais abatidos/mês; frigorífico B: 120 animais abatidos/mês; frigorífico C: 180 animais abatidos/mês), isso não resultou em uma diferença estatística significativa na produção desse tipo de resíduo. Logo, as preocupaçóes com o adequado destino dos resíduos sólidos devem ser as mesmas em todos os frigoríficos avaliados.

Os resíduos sólidos - como cabeças, restos de ossos e peles, restos de carcaças e vísceras condenadas e gorduras são destinados à fábrica de subprodutos, para terem posterior utilidade comercial na forma de farinhas. Esses resíduos são armazenados nos frigoríficos por 6 a 8 horas pós-abate e posteriormente transportados em caminhóes abertos sem proteção para a fábrica de subprodutos terceirizada, localizada em outro município vizinho, com distância não inferior a $25 \mathrm{~km}$ (Fig. 1). Nesse percurso e no interior dos frigoríficos é comum a presença desses resíduos espelhados pelo chão, com emissão de odor fétido, o que demonstra prática incorreta de armazenamento e transporte. A comercialização dos resíduos entre frigoríficos e fábrica de subprodutos ocorre apenas porque nenhum dos estabelecimentos dispóe de uma graxaria para processamento destes produtos e, o comércio (frigorífico $\mathrm{X}$ fábrica de subprodutos) se estabelece a preços baixos.

Tabela 1. Tipo e quantidade de resíduos sólidos gerados em frigoríficos que abatem bovinos na cidade de São Luís, Maranhão, 2012.

\begin{tabular}{lrrr} 
Tipo de & \multicolumn{3}{c}{ Quantidade média mensal $(\mathrm{kg})$} \\
\cline { 2 - 4 } resíduo sólido & Frigorífico A & Frigorífico B & Frigorífico C \\
Unhas & 3.700 & 4.440 & 6.660 \\
\hline Cabeças & 26.000 & 31.200 & 46.800 \\
\hline $\begin{array}{l}\text { Restos de ossos } \\
\text { Restos de carcaça }\end{array}$ & & & \\
$\begin{array}{l}\text { Restos de peles } \\
\text { Gorduras }\end{array}$ & 35.750 & 42.900 & 63.830 \\
Vísceras cruas & & & \\
\hline Esterco & 620 & 744 & 1.116 \\
\hline Total & 66.070 & 79.284 & 118.406 \\
\hline
\end{tabular}

Valor $p>0,05$
O Brasil tem intensificado sua política de participaçáo no Mercado Comum Europeu com exportação de carne de aves, bovinos e suínos. Dentre as restriçōes identificadas, percebe-se a exigência dos países importadores da não inclusão de matéria-prima animal na composição da ração, em razão de problemas de ordem sanitária, como é o caso da encefalopatia espongiforme bovina (EEB) e febre aftosa. Assim, as empresas deverão encontrar alternativas, buscando mercados consumidores para a carne brasileira, bem como mercados alternativos que reaproveitem os subprodutos das criaçóes comerciais (CAmpestrini, 2005; Padilha et al., 2006; DieHL et al., 2011).

Os outros resíduos sólidos, como as unhas, são armazenados em salas anexas ao setor de miúdos, nos frigoríficos, conservadas em cal virgem (óxido de cálcio) e mantidas por 40 a 60 dias nesses locais, em condiçôes insalubres que propiciam a proliferação de insetos e animais sinantrópicos, comercializadas com terceiros e encaminhadas para outros estados da federação. Já o esterco e os conteúdos estomacal e intestinal não digerido são armazenados próximo aos currais e ali permanecem até sua comercialização, por tempo variável. É comum a presença de moscas, que podem veicular patógenos aos animais, às carcaças e aos equipamentos e utensílios utilizados no abate.

Os tipos de resíduos líquidos derivados do abate de bovinos nos frigoríficos estudados e sua quantidade média mensal gerada estão discriminados na Tabela 2. Para o abate de bovinos, nos frigoríficos, grande quantidade de água é utilizada.

No frigorífico B, esses resíduos são removidos em caminhão pipa, com capacidade para 15 mil litros, e encaminhados à estação de tratamento, localizada a uma distância mínima de $7 \mathrm{~km}$ da empresa. Diariamente esse caminháo realiza de duas a quatro viagens para o transporte de todo o resíduo líquido gerado. Para os outros frigoríficos, os resíduos são imediatamente destinados à estação de tratamento, localizada no interior das indústrias.

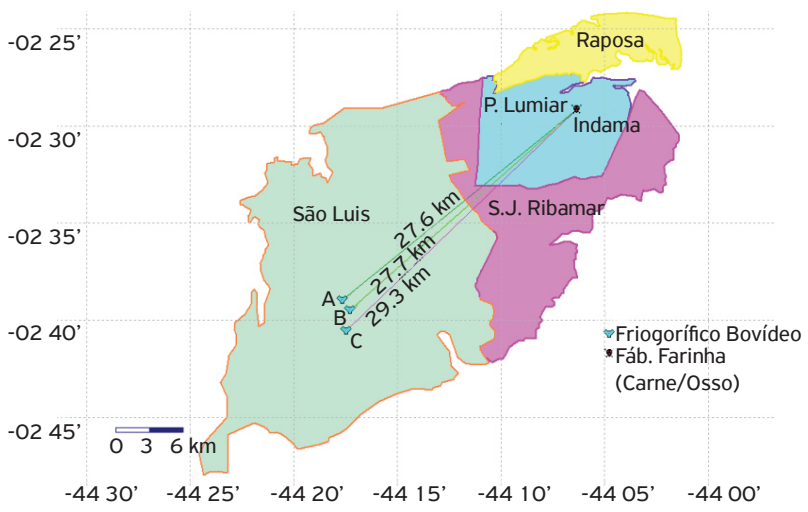

Figura 1. Distribuição espacial dos frigoríficos que abatem bovinos na cidade de São Luís, Maranhão, e distância desses em relação à fábrica de subprodutos, 2012. 
Em relação à avaliação estatística fundamentada na análise de variância (ANOVA) seguida do teste de Tukey, verificaram-se que existiam diferenças significativas $(\mathrm{p}>0,05)$ entre os frigoríficos quanto à produção de resíduos líquidos.

Para verificar se existia alguma relação entre a quantidade de resíduos líquidos gerados e a quantidade de animais abatidos nos frigoríficos, realizou-se a análise de correlação entre a quantidade de resíduos e a quantidade de animais abatidos. O coeficiente de correlação $(\mathrm{R})$ encontrado foi de 0,60 ; indicando que existe uma correlação moderada entre essas variáveis, ou seja, quanto maior o volume de abate, maior será a quantidade de resíduos líquidos gerados e lançados no meio ambiente. Logo, o frigorífico $\mathrm{C}$, pelo maior número de animais abatidos, também é o que mais produz e lança resíduos líquidos no ambiente.

Todo e qualquer resíduo sólido, semissólido ou líquido lançado no meio ambiente é regido por leis ambientais controladas por órgáos governamentais e que devem obedecer a padrôes de emissão, controlados por meio de análises periódicas e fiscalizaçóes constantes (PADilha et al., 2006). No caso da cidade de São Luís, Maranhão, os órgãos fiscalizadores ambientais são a Secretaria Municipal de Meio Ambiente (SEMMAM) e a Secretaria Estadual de Meio Ambiente (SEMA), ambas responsáveis pelo monitoramento e fiscalização das leis que regem os processos relacionados com emissão de cargas poluentes ao meio ambiente.
Outro fator que merece destaque na discussão da gestão ambiental no abate de bovinos é a legislação específica que fiscaliza a atividade. Os órgãos ambientais estaduais e municipais, na cidade de São Luís, têm atuado pouco na fiscalização das condiçôes de funcionamento das indústrias e de suas estaçóes de tratamento de efluentes. O resultado dessa fiscalização incipiente é demonstrado na Tabela 3, que discrimina os resultados das análises físico-químicas das amostras de efluente líquido das estações de tratamento dos frigoríficos avaliados, com exceção do frigorífico $\mathrm{C}$, que não permitiu a coleta do efluente.

Os resíduos líquidos são destinados para a "estação de tratamento de efluentes" dos frigoríficos e devolvidos ao corpo receptor sem tratamento, lançados diretamente no meio ambiente, próximos a residências e em manguezais. Em um dos frigoríficos não existe nenhum tipo de impermeabilização das lagoas, o que favorece a infiltração dos efluentes com possibilidades de contaminação do lençol freático.

Em apenas um frigorífico há a nítida separação ou segregação inicial dos efluentes líquidos em duas linhas principais: a linha "verde", que recebe principalmente os efluentes gerados na recepção dos animais, nos currais, na condução para o abate/"seringa", nas áreas de lavagem dos caminhóes, na bucharia e na triparia; e linha "vermelha", cujos contribuintes principais são os efluentes gerados no abate, no processamento da carne e das vísceras.

Tabela 2. Tipo e quantidade de resíduos líquidos gerados em frigoríficos que abatem bovinos na cidade de São Luís, Maranhão, 2012.

\begin{tabular}{lrrr} 
Tipo de resíduo líquido & \multicolumn{3}{c}{ Quantidade média mensal (kg) } \\
\cline { 2 - 4 } Sangue & Frigorífico A & Frigorífico B & Frigorífico C \\
\hline Efluente líquido & 52.000 & 62.400 & 93.600 \\
\hline Total & 2.200 .000 .000 & 2.600 .000 .000 & 104.000 .000 .000 \\
\hline
\end{tabular}

Valor $p>0,05$

Tabela 3. Resultados físico-químicos de amostras de efluentes líquidos de frigoríficos que abatem bovinos na cidade de São Luís, Maranhão.

\begin{tabular}{|c|c|c|c|c|c|}
\hline \multirow{3}{*}{ Parâmetros } & \multirow{3}{*}{ Unidade } & \multicolumn{4}{|c|}{ Resultados físico-químicos } \\
\hline & & \multicolumn{2}{|c|}{ Frigorífico A } & \multicolumn{2}{|c|}{ Frigorífico $\mathrm{B}$} \\
\hline & & $1^{\text {a }}$ coleta & $2^{a}$ coleta & 1a coleta & $2^{\text {a }}$ coleta \\
\hline Temperatura do ar & ${ }^{\circ} \mathrm{C}$ & 28 & 29 & 28 & 29 \\
\hline Temperatura da $\mathrm{H}_{2} \mathrm{O}$ & ${ }^{\circ} \mathrm{C}$ & 26 & 26 & 25 & 26 \\
\hline $\mathrm{pH}$ & & 8,0 & 8,0 & 8,0 & 7,0 \\
\hline Demanda bioquímica de oxigênio (DBO) & $\mathrm{mg} / \mathrm{LO}_{2}$ & 636 & 136 & 2611 & 210 \\
\hline Demanda química de oxigênio (DQO) & $\mathrm{mg} / \mathrm{LPO}_{4}$ & 2,080 & 7,140 & 84,160 & 14,280 \\
\hline Fosfato & $\mathrm{mg} / \mathrm{L}$ & 0,028 & 0,033 & 0,034 & 0,030 \\
\hline Óleos e graxas & $\mathrm{mg} / \mathrm{L}$ & 0,0120 & 0,0113 & 0,0115 & 0,0110 \\
\hline Sólidos suspensos & $\mathrm{mg} / \mathrm{L}$ & 80 & 60 & 70 & 50 \\
\hline Sólidos totais & $\mathrm{mg} / \mathrm{L}$ & 130 & 130 & 130 & 130 \\
\hline Sólidos dissolvidos & $\mathrm{mg} / \mathrm{L}$ & 60 & 60 & 60 & 60 \\
\hline Sólidos sedimentáveis & $\mathrm{mL} / \mathrm{L} / \mathrm{h}$ & 0,3 & 0,2 & 0,4 & 0,3 \\
\hline Sulfito & $\mathrm{mL} / \mathrm{L} / \mathrm{S}^{-}$ & 0,53 & 0,62 & 0,78 & 0,63 \\
\hline Nitrito & $\mathrm{mL} / \mathrm{L} / \mathrm{N}$ & 1,20 & 1,25 & 1,35 & 1,22 \\
\hline Nitrato & $\mathrm{mL} / \mathrm{L} / \mathrm{N}$ & 22,1 & 22,4 & 24,7 & 23,1 \\
\hline
\end{tabular}


As indústrias precisam estar atentas à legislação a que estão sujeitas para evitar não somente as multas mas, sobretudo, a associaçáo da sua imagem à degradaçáo do meio ambiente numa sociedade cada vez mais sensível às questôes ambientais. $\mathrm{O}$ fato é que a questão ambiental é permanente hoje, e as empresas de qualquer ramo de atividade têm de se adaptar à nova realidade e transformá-la em oportunidade (Padilha et al., 2006).

Com base nas condiçóes de lançamento de efluentes por parte dos frigoríficos, esses atendem à Resolução no 430 do CONAMA (BrasiL, 2011) nos seguintes parâmetros: pH, temperatura da água, sólidos sedimentáveis, óleos e graxas. E estáo em desconformidade com a referida resolução nos parâmetros: sólidos suspensos, $\mathrm{DBO}$ e vazâo máxima.

Fragmentos de carne, de gorduras e de vísceras foram os sólidos suspensos visualizados nos efluentes de todos os frigoríficos avaliados. Esses resíduos conferem odor fétido aos efluentes e geram uma imagem negativa na população em relação aos frigoríficos. Esses, por sua vez, não controlam o regime de lançamento dos efluentes e não sabem informar a vazão máxima nas lagoas ao longo dos meses.

A alta concentração de $\mathrm{DBO}$ pode ocasionar graves problemas ambientais. Como a DBO corresponde à alta quantidade de matéria orgânica no meio, para sua total decomposição há o uso do oxigênio dissolvido na água, caso a matéria orgânica seja muito abundante, a decomposição pode ser anaeróbia, tendo como resultado substâncias que podem degradar a qualidade da água. Os produtos mais comuns envolvidos na degradação anaeróbia são gás carbônico, metano, amônia, ácidos graxos, mercaptanas, fenóis e aminoácidos. A total depleção do oxigênio dissolvido ocasiona a morte da biota aquática dependente do oxigênio e eutrofização do corpo d'água (Pereira, 2004; Lima et al., 2006).

Para dimensionar ou controlar os processos de tratamento do efluente é importante avaliar sua biodegradabilidade, relacionando a DBO com a DQO (Pereira, 2004; Lima et al., 2006). Para o frigorífico A, no período avaliado a relação $\mathrm{DBO} / \mathrm{DQO}$ variou de 0,30 a 0,01 . Já para o frigorífico $\mathrm{B}$, no mesmo período, os valores variaram de 0,03 a 0,01 ; o que classifica os efluentes de ambos os frigoríficos como de difícil tratamento biológico ou de difícil biodegrabilidade.

Dos funcionários entrevistados, apenas os responsáveis técnicos pelos frigoríficos conhecem a importância do tratamento de efluentes e alguma legislação para a produçáo de resíduos sólidos e líquidos. Todas as empresas possuem Programa de Controle Ambiental (PCA), entretanto, desatualizados, e apenas uma possui Plano de Gerenciamento de Resíduos Sólidos (PGRS), também nas mesmas condiçôes.

Foram analisadas também as ações empreendidas e a postura da empresa com relação às questôes ambientais.
Dessa forma, constatou-se não ser uma preocupação das empresas manter o seu processo produtivo sem causar danos ao meio ambiente. As empresas têm pouca ou nenhuma consciência do que produz em termos de resíduos; não sendo clara a sua responsabilidade em trabalhar atendendo às normas reguladoras da questão ambiental. Nota-se, ainda, pouco ou nenhum investimento por parte das empresas no sentido de minimizar os danos ambientais gerados.

As empresas, com seus mecanismos de proteção ao meio ambiente e em consonância com a legislação específica devem, em sua própria planta, dar um fim a esses resíduos de forma que náo agridam ou poluam o meio ambiente. As empresas que desejam crescer e se manter no mercado como líderes na industrialização devem buscar maneiras mais eficientes de diminuir seus custos, bem como demonstrar preocupação ecológica (PADilha et al., 2006).

\section{CONCLUSÕES}

Com base nos resultados obtidos nesta pesquisa pode-se concluir que:

- Os resíduos sólidos e líquidos dos frigoríficos na cidade de São Luís, Maranhão, são poluidores, sobretudo no que se refere aos altos teores de matéria orgânica presentes, difícil biodegradabilidade e alto consumo de água;

- O efluente dos frigoríficos é responsável por uma imagem negativa do público em relação a esses estabelecimentos, principalmente pelo odor fétido presente na circunvizinhança;

- Os frigoríficos devem ter um adequado manejo ambiental dos seus resíduos e implantar alternativas de produção sustentável, adequando o processo industrial às condiçôes e legislaçóes ambientais;

- Os empresários devem se conscientizar e procurar alternativas para minimizar seus impactos ao meio ambiente;

- O desenvolvimento sustentável através do uso de mecanismos de desenvolvimento limpo tornou-se de vital importância para a saúde publica, para combater a poluição das águas e com isso as indústrias minimizam os custos e geram renda.

\section{AGRADECIMENTOS}

À Pró-reitoria de Extensão e Assuntos Estudantis (PROEXAE) da Universidade Estadual do Maranhăo (UEMA) pela concessão de bolsa de extensão para a realização deste trabalho. 


\section{REFERÊNCIAS}

ABIEC. ASSOCIAÇÃO BRASILEIRA DAS INDÚSTRIAS EXPORTADORAS DE CARNE. Perfil da pecuária brasileira, 2011 . São Paulo: ABIEC, 2011 . Disponível em: <http:// www.abiec.com.br/download/fluxo_por.pdf $>$. Acesso em: 23 dez. 2012.

ABNT. ASSOCIAÇÃO BRASILEIRA DE NORMAS TÉCNICAS. Preparo de amostras para exame microbiológico. NBR 10203. Rio de Janeiro: ABNT, 1988. 3p.

ABNT. ASSOCIAÇÃO BRASILEIRA DE NORMAS TÉCNICAS. Resíduos sólidos: classificação. NBR 10004. Rio de Janeiro: ABNT, 2004. $71 \mathrm{p}$.

APHA. AMERICAN PUBLIC HEALTH ASSOCIATION. Standard methods for the examination of water and wastewater. 19th. ed. Washington: APHA, 1995. 48p.

ARANGO, H.G. Bioestatística teórica e computacional: com bancos de dados reais em disco. Rio de Janeiro: Guanabara Koogan, $2001.236 p$.

ARAÚJO, G.C.; BUENO, M.P.; MENDONÇA, P.S.M. A sustentabilidade em frigoríficos: discussão de um estudo de caso. In: XLV CONGRESSO DA SOCIEDADE BRASILEIRA DE ECONOMIA, ADMINISTRAÇÃO E SOCIEDADE RURAL, 2007, Londrina, PR. Resumos. Londrina: 2007. p. 1-15.

BRAILE, P.M. Manual de tratamento de águas residuárias industriais. São Paulo: CETESB, 1993. 764p.

BRASIL. CONSELHO NACIONAL DO MEIO AMBIENTE (CONAMA). Resolução № 430, de 13 de maio de 2011. Dispõe sobre as condições e padrões de lançamento de efluentes, complementa e altera a Resolução n 357, de 17 de março de 2005, do Conselho Nacional do Meio Ambiente - CONAMA. Diário Oficial da União, Brasília, 2011. 8p.

CAMPESTRINI, E. Farinha de carne e ossos. Revista Eletrônica Nutritime, v.2, n.4, p.221-234, 2005.

DIEHL, G.N.; ROSSATO, N.A.; KOHEK JÚNIOR, I.; DOMINGUES, R.D.; SOUZA, G.E. Fiscalização de alimentos de ruminantes em propriedades rurais no Rio Grande do Sul como medida para prevenção da Encefalopatia Espongiforme Bovina - EEB. Rio Grande do Sul: Departamento de Defesa Agropecuária, 2011. 4p. (Informativo Técnico n. 1 1, ano 2). Disponível em: < http:// www.dda.agricultura.rs.gov.br/ajax/download.php?qArquivo= 20130225111514 prevencao_da_encefalite_espongiforme_ bovina.pdf.>. Acesso em: 25 set. 2014.

FERNANDES, M.A. Avaliação de desempenho de um frigorifico avícola quanto aos princípios da produção sustentável. 2004. 120p. Dissertação (Mestrado em Administração) -Universidade Federal do Rio Grande do Sul, Porto Alegre, 2004.
IBGE. INSTITUTO BRASILEIRO DE GEOGRAFIA E ESTATÍSTICA, 2011 . Efetivo bovino. Disponível em: <http://www.ibge.gov.br/ estadosat $/$ temas.php?sigla $=$ ma\&tema $=$ censoagro $>$. Acesso em: 22 dez. 2012.

LIMA, L.D.; IZARIO FILHO, H.J.; CHAVES, F.J.M. Determinação de demanda bioquímica de oxigênio para teores $\leq 5 \mathrm{mg} \mathrm{L}^{-1} \mathrm{O}_{2}$. Revista Analytica, n.25, p.52-57, 2006.

MORALES, M.M. Avaliação dos resíduos sólidos e líquidos num sistema de abate de bovinos. 2006. 84p. Dissertação (Mestrado em Agronomia) - Faculdade de Ciências Agronômicas, Universidade Estadual Paulista, Botucatu, 2006.

NIETO, R. Caracterização ecotoxicológica de efluentes líquidos industriais: ferramenta para ações de controle da poluição das áquas. In: CONGRESSO INTERAMERICANO DE ENGENHARIA SANITÁRIA E AMBIENTAL, 2000, Porto Alegre. Anais. Porto Alegre: 2000. Disponível em: <http://www.abes-dn.org.br.htm>. Acesso em: 23 dez. 2012.

PACHECO, J.W. Guia técnico ambiental de frigoríficos: industrialização de carnes (bovina e suína). São Paulo: CETESB, 2006. 88p.

PACHECO, J.W.; YAMANAKA, H.T. Guia técnico ambiental de abate (bovino e suíno). São Paulo: CETESB, 2008. 95p.

PADILHA, A.C.M.; SILVA, T.N.; SAMPAIO, A. Desafios de adequação à questão ambiental no abate de frangos: o caso da perdigão agroindustrial - unidade industrial de Serafina Corrêa - RS. Teoria e Evidência Econômica, v. 14, edição especial, p. 109-125, 2006.

PEREIRA, R.S. Identificação e caracterização das fontes de poluição em sistemas hídricos. Revista Eletrônica de Recursos Hídricos, v.1, n.1. p.20-26, 2004.

PRATA, L.F. Manual de inspeção higiênico-sanitária e tecnologia de carnes, pescado e derivados. Jaboticabal: FUNEP, 1999. 217 p.

RIBEIRO, G. Os homens que não copiavam. Adiante: Inovação para Sustentabilidade. São Paulo: FGV-CES, n.4, 2006.

SARDA, S.E.; RUIZ, R.C.; KIRTSCHIG, G. Tutela jurídica da saúde dos empregados de frigoríficos: considerações dos serviços públicos. Acta Fisiátrica, v. 16, n.2, p.59-65, 2009.

SEVERO, L.S.; DELGADO, N.A.; PEDROZO, E.Á. A emergência de "inovações sustentáveis": questão de opção e percepção. In: SIMPOSIO DEADMINISTRAÇÃO DA PRODUÇÃO, LOGÍSTICA E OPERAÇÕES INTERNACIONAIS, 9, 2006, São Paulo, SP. Anais. São Paulo: 2006.

SILVA, A.N. Manejo de resíduos sólidos industriais: frigorífico de Araguaína - TO. 2011 1.58p. Trabalho de Graduação (Graduação em Administração) - Faculdade de Economia, Administração e Contabilidade, Universidade de Brasília, Palmas, 2011. 